\title{
Elbasani në syrin e udhëtarëve të huaj
}

\author{
Vilma Tafani
}

Jo pak udhëtarë të huaj kanë kaluar apo kanë qëndruar me ditë në Elbasan, duke provuar kështu mikpritjen elbasanase. Janë të shumta faqet që janë shkruar, mbresa e kujtime për Elbasanin dhe për familjet elbasanase. Duke shfletuar libra të ndryshëm në bibliotekat e universiteteve të ndryshme, jam ndeshur me libra, përshkrime, ilustrime, fotografi e mendime të cilat m `u dukën me interes që dhe bashkëqytetarët e mi t'i njohin, ndaj dhe vendosa të bëj sadopak një përpjekje modeste në radhoin e librave Elbasani në shekuj. (V. T.)

\section{“Dy endacakë nëpër Shqipëri”, Jan Gordon, 1927}

Libri "Dy endacakë nëpër Shqipëri”, i shkruar nga Jan Gordon dhe bashkëshortja e tij Kora (Cora) Gordon, është botuar më 1927. Autorët e përshkruajnë Shqipërinë e vitit 1925 (koha e qëndrimit të tyre në Shqipëri) si një vend gjysmëlindor, gjysmëperëndimor që po përpëlitej të formonte shtetin e vet. Kronika e tyre e udhëtimit dallohet për saktësinë e fakteve, objektivitetin e rrëfimit, si dhe ilustrimet e përshkrimeve me fotografi të bëra nga vetë ata.

Që në hyrje të librit ata shkruajnë: "Komedia që ne kemi parë në këtë vend, $i$ takon, sipas mendimit tonë, këtij vendi, kësaj province, ku komedia përligjet plotësisht...”.

Një pjesë e konsiderueshme e rrëfimit në këtë libër i kushtohet qytetit të Elbasanit, ku autorët kanë qëndruar më shumë se një javë. Përshkrimi fillon me ngjitjen e tyre të mundimshme në Qafën e Krrabës, një ngjitje që duket e pafund, shumë e ngadalshme, nën rrezet e diellit që u verbonte sytë dhe të nxehtit që u përvëlonte ballin. 


\section{Albanon}

Nganjëherë, kur ngjitja ishte shumë e përpjetë, ata zbrisnin nga kuajt dhe vazhdonin rrugën më këmbë. Kjo gjë e çudiste shumë shoqëruesin e tyre shumë plak, Myslim Haxhiun, që pëshpëriste me vete:

"Përderisa kanë marrë me qira kuaj, pse nuk i ngasin ata vazhdimisht? Pse u vjen keq dhe kursejnë një kalë që nuk është $i$ tyre?”.

E ndërkohë që ai mendonte me sarkazëm në heshtje, se kali që ishte marrë me qira nuk duhej të kursehej, se kështu do të ishte edhe më mirë për atë që i kishte dhënë kuajt, që t’i fitonte paratë me mund dhe jo kot, udhëtarët $\mathrm{e}$ huaj mendonin ndryshe. Ata mendonin se i kishin shfrytëzuar kuajt shumë, kishin kalëruar aq shumë, saqë një gjë e tillë do të ishte e pamundur për kuajt në Angli.

Edhe zbritja nga Qafa e Kërrabës u duket udhëtarëve po aq e lodhshme dhe e mundimshme, sa edhe ngjitja. Në zbritje ata do ta kenë diellin përvëlues në shpinë, prapa qafës:

"Një pasdite e kuqe, përvëluese që të pjek. Dielli pasi ka thithur tërë lagështinë e gjithë mjedisit përreth, e ka drejtuar gjithë vëmendjen e tij ndaj nesh, duke hedhur drejt nesh gjithë rrezet e fundit të nxehta të ditës, duke na tharë me nxehtësinë e tij e duke na bërë si rosa Bombei të pjekura. Zbrisnim e zbrisnim, të shumtën e kohës ecnim, pengoheshim, rrëzoheshim e përsëri ngriheshim. Nxehtësia na godiste nga të gjitha anët, nga lart dielli, nga poshtë nxehtësia e gurëve. Vapa e tmerrshme na depërtonte si rrymë e nxehtë nga çdo drejtim, ajo depërtonte në çdo qelizë të trupit tonë... Ishte e pamundur të ndaloje gjëkundi, nuk kishe ku të fusje kokën. Megjithatë ne ndaluam një apo dy herë dhe mezi merrnim frymë të stërlodhur dhe të frikësuar nga rreziku i dehidratizimit. Bukuria e peisazhit nuk na hynte në sy fare. Nuk ishte ndonjë kënaqësi e madhe të ndaloje e të shijoje bukurinë duke qëndruar mbi "një furrë pjekjeje”. Shumë mund të mendojnë kur të lexojnë këto rreshta se ne ishim udhëtarë të vërtetë plangprishës të panoramave përvëluese...".

Ata mbërrijnë në qytet në perëndim, të përvëluar dhe shumë të etur. Në pamjen e parë Elbasani do t'u duket si një qytet në rënie. Disa pemë në hyrje të tij ishin të mjaftueshme për të fshehur pothuajse krejt pamjen e qytetit, përveç dy minareve të bardha që ngriheshin mbi çatitë e shtëpive dhe të vetmet që kishin mbijetuar nga tërmeti i fundit. Në horizont dukeshin edhe disa qiparise që me sa duket rrethonin vendin e 'lutjeve`. Të hysh në një qytet të huaj, vazhdimisht është një nga përvojat më të pakëndshme për këdo, ku zakonisht të pret një hotel, një darkë e ftohtë dhe një gjuhë e çuditshme, e pakuptueshme, dhe gjendja e dy udhëtarëve mund të kuptohet 
më mirë sikur këtyre gjërave t’u shtosh edhe lodhjen e tmerrshme të një udhëtimi sfilitës e përvëlues, ku të thahej buza për një "bulëz" ujë.

Që kur ishin në rrethinat e qytetit ata vunë re muret e kalasë dhe kur u afruan, panë se nuk kishte hapësira boshe, tipar që karakterizonte gjithë qytetet myslimane. Dhe shumë shpejt u ndodhën në labirinthet e pazarit. U lindi dëshira të dilnin nga ky pazar, por nuk dinin se si, kuajt po i ndiqnin në heshtje. Kështu, të dy udhëtarët anglezë, të sikletosur dhe si të zënë në faj, ecnin prapa Haxhiut dhe kuajt pas tyre. Ata ecnin duke zvarritur këmbët dhe u dukej sikur po merrnin pjesë në ndonjë procesion mysliman. Kjo gjë i bënte ata me të dukshëm në sytë e vendasve duke tërhequr gjithnjë e më shumë vëmendjen e tyre. Ata i kaluan rrugët e qytetit në heshtje, duke u drejtuar drejt hanit të vetëm të qytetit, për të cilin shoqëruesi i tyre mendonte se ishte një gjetje e përshtatshme për ta.

Myslimanët vendas, me solemnitet nxirrnin kokat e tyre nga dyqanet e vogla dhe shikonin udhëtarët e huaj, në kohën kur ata parakalonin para dyqaneve të tyre. Dhe ata kalonin të heshtur, të ndjekur nga kurioziteti i njerëzve. Kokat e udhëtarëve anglezë pothuajse arrinin strehëzat e dyqaneve të tyre të vegjël.

Shoqëruesi i ndaloi ata përpara një shtëpie. Shtëpia nga jashtë dukej e këndshme, por nga brenda ishte një stallë e vërtetë, pa ndriçim dhe pa ajrosje. Por ata s` kishin ç` të bënin tjetër, veçse të hynin në hotelin e 'përshtatshëm’. Ata mbetën disi të zhgënjyer dhe ishin shumë të shqetësuar për të papriturat që po i ndiqnin dhe për ato që do të vinin më vonë.

Hynë brenda, u ngjitën lart nëpër një shkallë të vjetër që të çonte në katin e sipërm. Atje gjetën një dhomë të madhe si haur me nëndarje të vogla, që ata i quanin dhoma gjumi, të cilat ndaheshin nga njëra-tjetra me kallamishte e horasan, dhe dukeshin si 'hojet e bletëve’ kur janë bosh.

Autori e përshkruan kështu të zotin e hanit: "Ai ishte një burrë muskuloz, $i$ parruar, me një qeleshe të bardhë në kokë dhe me një shami të verdhë. Ai kishte veshur një xhamadan të zi, këmishë blu, brez të kuq, pantallona ngjyrë kafe dhe çorape jeshile. Në dorë mbante një orë argjendi shumë të madhe dhe dy unaza argjendi, edhe këto shumë të mëdha. Në qafë kishte një varëse...”.

Hanxhiu u tha udhëtarëve çmimin e dhomës dhe ata mbetën të kënaqur: ishte një çmim i mirë dhe i kënaqshëm për ta. Ata paguan shoqëruesin e tyre, madje i dhanë edhe bakshish, për të cilin ai u kënaq më shumë. Të dy udhëtarët anglezë vendosën të qëndronin në Elbasan përreth një javë. 


\section{Albanon}

Sipas modës lindore, ata mund të kishin dhënë porosi që t’u shërbehej ushqimi në dhomë, sepse megjithëse hotel Adriatiku ishte një lloj hani me një oborr të madh për të strehuar edhe karvanet, disa djem, që paguheshin shumë pak, për hiçgjë, e bënin shumë të lehtë jetën në hotel, madje në të gjithë qytetin, duke lehtësuar shërbimin në restorantet e vogla të një qyteti të tillë. Një shërbim i tillë, që merrte zanafillën nëpër restorante, shtonte klientelën më shumë jashtë sesa brenda hoteleve. Në çdo kohë mund t`i shihje këta djem, duke rendur rrugëve të qytetit në drejtim të klientëve, me enë të mbuluara, duke e bërë kështu furnizimin me ushqim të gatshëm më të lehtë për ata që lëshonin shtëpitë e tyre me qira, duke e zgidhur në një farë mënyre problemin e gatimit.

Por, megjithëse të dy udhëtarët ishin të lodhur, ata parapëlqyen më mirë "të gjuanin” (të dilnin për të kërkuar vetë) ushqimin e tyre për të parë e shijuar përvoja të reja.

Dielli kishte perënduar që kur ata kishin hyrë në Elbasan dhe në kohën që ata u sistemuan në dhomë, muzgu kishte rënë plotësisht mbi rrugët e qytetit. Dyqanet po mbylleshin dhe ca drita të zbehta e misterioze ndihmonin dyqanxhinjtë e fundit me qeleshe, të cilët ende po rrekeshin me shumë mund, të kërrusur, të përfundonin detyrat e mbrëmjes. Llampat e vogla me vajguri ndriçonin rrugët, aq sa mund të ndriçonte oqeanin një fanar. Duke pasur shumë besim në fatin e tyre, ata dolën shëtitje "në këtë Elbasan që po errësohej".

Pasi kaluan nja dy kthesa, u gjendën fare papritmas përpara një ndërtese që gjykuan se mund të ishte restorant tipik vendas. Arkitektura e kësaj ndërtese ishte aq e vjetër, dhe me punime druri aq të rrahura nga koha, saqë ata pyetën veten se si kjo ndërtesë mund t’i kishte qëndruar gjithë asaj historie që dukej se mbante mbi shpatulla. Megjithëse e lyer me gëlqere të bardhë, ajo më shumë e përforconte sesa e fshihte rrënimin e përgjithshëm të ndërtesës. Një bllok tullash në lartësinë e dritares, dhe diçka e sheshtë metalike në formën e kovës ruante nxehtësinë*. Ky masiv qëndronte mbi një si kanal të mbushur me qymyr, që nxirrte një flakë me ngjyrë të çuditshme. Dy tavolina të gjata me stola të gjatë anash, me sa dukej prisnin miqtë, që ende nuk kishin ardhur, ose, mbase për shkak të `erës jo të këndshme që kishte ky vend’, ndoshta nuk do të vinin kurrë. Një llambë e vogël me vajguri, që digjej mirë dhe tymi që nuk ndihej dhe aq, i jepte errësirës një ngjyrë të kuqe më shumë si të flakës sesa për ta ndriçuar.

*Me sa duket e ka fjalën për oxhakun, shënim i V.T. 
Të dy udhëtarët, kur panë këtë pamje "mund të kishin luftuar me stomaqet" e tyre e të largoheshin, por tundimi ishte i pashmangshëm. Ata ishin aq të uritur saqë nuk donin t’ia dinin për asgjë dhe hynë brenda pa ngurruar. Megjithatë, nuk iu desh shumë 'të luftonin` me urinë, pasi gatimi ishte më i mirë nga ç'të krijonte idenë pamja e restorantit dhe pak a shumë i shijshëm. Më tej ata shkruajnë: "Mё në fund e mundëm urinë, në mënyrë të kënaqshme, hëngrëm mirë, u rehatuam në stol dhe pyetëm në shqip, me atë shqipe që ne mendonim se ishte shumë e mirë dhe e mjaftueshme për t'u marrë vesh .

- Sa kushton?

Dy çunat gjatoshë dhe thatimë, me përparëse pambuku me ngjyrë, u këshilluan me njëri-tjetrin në qoshen e errët.

- Njëzet e dy - tha njëri më në fund.

- Njëzet e dy, çfarë? - pyetëm.

- Vienti due - tha njëri në italisht.

- S'di italianski - tha Xho, gruaja e anglezit.

- Unë nuk di italisht, flas shqip, njëzet e dy çfarë?”

Ishte e domosdoshme të pyesje e të kërkoje sqarime për këtë numër "njëzet e dy", të pashoqëruar me asnjë fjalë tjetër. Në Durrës ata kishin paguar me lireta italiane, ndërsa në Tiranë lireta italiane nuk ishte në qarkullim, atje përdoreshin vetëm monedha floriri dhe argjendi. Nëse ata do të paguanin në lireta, darka do t’u kushtonte rreth katër shilinga angleze, por nëse do të paguanin në korona argjendi, ajo do t’ u kushtonte tetë shilinga. Ata nuk ishin të sigurt nëse Elbasani do të kishte ndonjë standard të vetin apo monedhë lokale. Prandaj ata e përligjën veten kur kërkonin informacion më të saktë.

Pas përpjekjeve të kota për të kuptuar ndonjë fjalë të tyre, anglezi i dha njërit prej djemve një monedhe floriri dhjetëfrangëshe. Të dy udhëtarët po prisnin me kureshtje rezultatin. Monedha e floririt kishte vlerën e njëzet e dy koronave, ose të dyzet e katër liretave. Në fakt anglezi po priste që djali t’ $i$ kthente njëmbëdhjetë korona kusur, por djaloshi e futi monedhën në xhep, u përkul dhe doli jashtë në errësirë.

"Me sa duket - tha gruaja ndërkohë që të dy po ecnin ngadalë mbi kalldrëm në drejtim të shtëpisë, - Elbasani do të jetë shumë i shtrenjtë për ne. Kam frikë se nuk do të mund të rrimë gjatë këtu, dhe kjo është më se e qartë dhe e sigurt."

Kur të dy udhëtarët mbërritën në hotel Adriatik, i zoti i hotelit, i veshur mirë, por i parruar, u ngrit nga një kanape e rehatshme që ishte në zyrën e 


\section{Albanon}

tij, e cila ishte në formën e një kthine, që t $\mathrm{i}$ uronte dy miqve "natën e mirë". Tashmë të 'shkretët' miq duhet të rehatoheshin në një divan, në atë "stallë të zezë që nuk ishte gjë tjetër veçse vend plehu.".

Ata u mbështollën kokë e këmbë me pelerinat e tyre, por me gjithë përpjekjet, këmbët u mbeteshin jashtë. Dhoma e tyre ishte si një dhomëz bletësh, e ndriçuar nga një qiri. Ranë në krevat pa optimizmin e nisjes. Megjithatë, e ndienin se frika e tyre ishte pa bazë.

Për përshtypjet e tyre për Elbasanin, ata shkruajnë: "Elbasani ka shumë pak shenja të qytetërimit evropian. Pazari ka një hare të dukshme, veshje shumëngjyrëshe që janë karakteristike për Lindjen. Dhomat e vogla shërbejnë në të njëjtën kohë edhe si dyqane edhe si punishte, ato janë të zbukuruara me drita të shndritshme dhe sendet e ndryshme për tregti janë të vendosura me rregull dhe në vende të dukshme. Vetë pronari punëtor ka më shumë kujdes për to, sesa për t`i krijuar vetes komoditetin e duhur.

Më tej, autori vazhdon përshkrimin e fshatarit: "Përmes rrugëve, me gomarin e ngarkuar me prodhimet e veta, fshatari ecën ngadalë, i veshur me kostumin e tij bardhë e zi, duke mbajtur një shami shumëngjyrëshe e me ngjyra të ndezura. Disa ende veshin pallton e tyre të leshtë, të zezë, që është shenjë zie për vdekjen e heroit të tyre, Skënderbeut. Borgjezia që sa po lind, mban një lloj festeje të zezë karakteristike shqiptare, e cila aktualisht duket si një kapele e butë me strehë të prerë. Ndërsa tingujt që i shkonin mjedisit dhe spektaklit që po zhvillohej, të kujtonin një lloj muzike të vazhdueshme që i ngjante ritmit të kafexhiut shëtitës, që lajmëronte ardhjen e tij. Më karakteristike për vendin ishte zëri $i$ lodhur dhe i ngjirur $i$ akullorexhiut që thërriste: E ftohtë si bora, kush do të freskohet?".

Në Elbasan ata kishin pajtuar një shoqërues për t’i ndihmuar sadopak, e drejtuar në këtë ndërmarrje aventureske. Shtëpia e shoqëruesit, nuk ishte ndryshe nga të tjerat, me një portë të stërmadhe që nuk dukej aspak mikpritëse, një sallon si hyrja e një hani të vjetër, me punime druri çuditërisht të gdhendura sipas modelit turk, prapa të cilave mund të shihje fragmente të një oborri me shenja të çuditshme për të tërhequr vëmendjen e vizitorëve.

Dhoma e pritjes ishte një përzierje e rastësishme e një dhome pritjeje, biblioteke dhe muzeumi. Muret ishin mbushur plot e përplot me një koleksion heterogjen, që nga lloje të ndryshme zogjsh, e deri te gjërat antike prej argjendi. Edhe raftet ishin të mbushur me objekte argjendi, fosile, copëza objektesh të gdhendura, monedha të vjetra, varëse të ndryshme që largonin xhindet, nuska, libra të vjetër, armë etj. Në fakt, ata kështu e kishin 
imagjinuar dhomën, të cilën prisnin ta shihnin në shtëpinë e parë shqiptare që do të hynin, sapo të shkelnin në Shqipëri.

Diletanti (kështu e quan autori shoqëruesin, shënim V.T.), të cilit ata i sollën një letër prezantimi, dukej shumë më pak nga shqiptari imagjinar, që ata kishin në mendje. Imazhi i tij nuk mbante aspak karakteristikat e mundshme fizike që u kishin dhënë atyre për shqiptarët. Ai ishte një shqiptar trupvogël. Kishte qenë dy herë në burg dhe gjithashtu, për ca kohë edhe kryetar i Bashkisë së Elbasanit.

Në kohën kur dy udhëtarët anglezë vizituan shtëpinë e tij, Diletante ishte tërhequr plotësisht nga politika dhe ishte bërë një koleksionist i apasionuar, duke pasur si qëllim të fundmë t’ i linte koleksionin e tij qytetit të tij.

Vizita te zyra e prefektit shënoi hapin e parë për udhëtarët e huaj për të cilët vizita në Shqipëri filloi të marrë një karakter më vetjak. Ishte Diletante, ai që i çoi ata në vizitë ceremoniale te zyra e prefektit, për të paraqitur letrat e tyre të prezantimit ministror, zyrtarisht. Ata pinë kafet e ëmbla që ishin zakonisht hapja e ceremonisë zyrtare. Prefekti, një burrë zeshkan, me mustaqe të gjata, me fytyrë të stërgjatë, e shprehte hapur habinë kur Xho (gruaja) belbëzonte fjalë në shqip, pasi njohuritë e saj për gjuhën shqipe ishin shumë të kufizuara. Ai shprehu falënderimet e tij dhe mirënjohjen që i buronte nga zemra për ardhjen e tyre në Shqipëri dhe aq më tepër, që ata do të shkruanin për Shqipërinë. Prefekti vuri në dispozicion e tyre, falas, gjithçka kishte, veturën e tij, kuajt, policinë dhe gjithë burimet e tjera që i ofronte posti.

Gjatë bisedës, duke dredhur mustaqet e tij, ai u tha dy miqve angleze: "Tani më thoni të vërtetën, sa paguat mbrëmë për darkën?”.

Kjo pyetje i la të shtangur dy miqtë. Ata nuk kishin folur me asnjë njeri për këtë çështje.

“- A është e vërtetë, që paguat gjysmë napoloni?

- Po, ashtu është.

- Aha, e dëgjova këtë - tha prefekti me një buzëqeshje krenare, triumfuese. - Tani më thoni çfarë hëngrët? Sa pjata?”

Ata i treguan atij me hollësi se çfarë kishin ngrënë, supë, bukë, mish, pilaf, dhallë dhe një shishe birrë.

Prefekti e bëri llogarinë me gishta, e vlerësoi darkën njëmbëdhjetë ose dymbëdhjetë korona dhe pastaj me një zemërim që sapo vinte e po i shtohej, tha: "Sa e tmerrshme, si mund të ndodhë kështu, duhet ta shoh këtë punë. Më 


\section{Albanon}

vjen sinqerisht turp. Ju kërkoj falje në emër të gjithë shqiptarëve të ndershëm”. Të dy miqtë u vunë disi në siklet nga fjalët e sinqerta të prefektit.

Por ky ritual pyetjesh për darkën e parë dhe "mashtrimin" i ndoqën dy miqtë gjatë gjithë qëndrimit të tyre në Elbasan, në çdo takim që patën më pas me kryetarin e bashkisë, me juristin, beun, etj. Kjo gjë i shastisi miqtë. Ç’ po ndodhte kështu? Kërkesa e faljes e njërit apo tjetrit ishte me takt. Të dy udhëtarët ndiheshin të shokuar.

Takimi me juristin i la mbresa. Autori mendon se juristi ishte gjenial, i mprehtë, me personalitet dhe për më tepër, ishte në dijeni të të gjitha gjërave që ndodhnin në qytet. Dy miqve iu desh të pinin përsëri kafen e tyre ceremoniale, e pesta atë mëngjes. Ishte e çuditshme se juristi, për të porositur kafenë e tyre, i thirri dikujt në rrugë. Nuk kaloi shumë kohë dhe kafja erdhi në një tabaka mbi dy shufra prej hekuri në formën e një mashe... Kërcitja e shufrave metalike që kryenin funksionin e mashës, ishte zhurmë karakteristike vetëm për Elbasanin, por dy miqve nuk iu duk se ishte me origjinë vendase. Ata mendojnë se ky zakon duhet të kishte ardhur këtu nga Konstandinopoja. Kafexhiu e mbante kafenë në një tabaka metalike, disi të çuditshme që varej nga lart. Në njërën anë të saj ishin një grumbull thëngjijsh qymyri të ndezur, që ngrohnin disa xhezve kafeje të vogla, me bishta të gjatë dhe të hollë si furçat e piktorit. Nga ana tjetër e tabakasë, qëndronin në radhë disa filxhanë të vegjël kafeje. Pranë dorezës së tabakasë kishte ca copa shkumësi, me të cilat shënonte me vija numrin e kafeve që bënte. Ndërsa me mashën që lëshonte tingujt muzikorë, ai trazonte herë pas here qymyrin që digjej. Pasi e përzieu kafenë e nxehtë në xhezvet e vogla, kafexhiu zbrazi lëngun e zi në filxhan dhe ia drejtoi Xho-së. Për çdo filxhan, kafeja bëhej veç e veç, që të mbante shkumën. Ndërkohë që miqtë po thithnin me kënaqësi kafenë, kafexhiu iu afrua rafteve të librave në të cilat kishte vetëm ca libra të mëdhenj të zhubrosur dhe ca pirgje gazetash që ishin mbuluar me pluhur.

Thuhej se në Elbasan mbledhësi i taksave të të ardhurave, nëse do të kishte një njeri të tillë, do të mund të llogariste biznesin e kujtdo në Elbasan, në bazë të numrit të kafeve që ai pinte në muaj. Dhe kjo thënie për Elbasanin, u dukej më se e vërtetë të dy miqve anglezë.

Nga juristi, Diletante i çoi të dy miqtë në një restorant tjetër shkatarraq nga pamja, por ku Shqipëria nuk "rrezikohej të turpërohej përsëri”. Dhe me të vërtetë, ata u kënaqën shumë aty. Selimi, pronari i restorantit, që autori e quan "dyqan të vogël gatimi”, as që e mori mundimin të përfitonte nga të huajt që flisnin një gjuhë të çuditshme. Shqiptari “jo i sofistikuar”, siç ishte 
në atë kohë, duhet të merrte role të ndryshme nga Europa moderne, ai duhet të mësonte të fshehtat e zanatit, të mësonte ç’ishte spekulimi, të dinte të veçantat e pronës private, të dinte të vendoste çmime të larta mbi koston, të mësonte mashtrimin, vjedhjen e moderuar, profesione që relativisht ende nuk i kishte mësuar.

Mashtrimi, korrupsioni, spekulimi zyrtar, vjedhja me të madhe, mund të konsideroheshin në atë kohë më shumë si domosdoshmëri sesa vese, në një shtet të tillë plot turbullira siç ishte Shqipëria, me një burokraci që ishte e justifikueshme ("- Dhe s'ka se si të shpjegohet ndryshe - thoshte autori, ndërsa prefekti merr zyrtarisht 150 dollarë në vit, me kaq e mban ai shtetin?”) dhe varfëri të tejskajshme.

Restoranti i vogël i Selimit, kështu do ta quajmë 'dyqanin e tij të gatimit', për të cilin autori thotë se është shumë të quhet restorant, nuk ishte më tërheqës në pamje sesa tjetri. Njëra faqe e restorantit ishte plotësisht e hapur. Punimet me dru ishin të vjetra dhe shumë të amortizuara. Gëlqerja e bardhë me të cilën ishte lyer restoranti, vetëm emrin e kishte të bardhë, por ushqimi gatuhej mirë, nuk kishte të sharë. Hapësira ishte aq e ngushtë saqë mund të qëndroje përjashta në rrugë dhe në të njëjtën kohë 'të fusje hundët në kuzhinë, të shikoje ç'kishte mbi sobë dhe të zgjidhje cffarë gjelle dëshiroje, të nxehtë, nga tigani.

“ - Gjellët ishin të çuditshme - kujton autori - supëra që nuk i kishim provuar ndonjëherë, me erëza që përmbanin shumë acid, çorbë, gjellë të ndryshme të ziera, qebab, pilaf, domate dhe speca të mbushur, makarona spageti, salcë kosi ose fërgesë. Ndërsa pas buke, përdornin shpesh dhallë dhe hanin si ëmbëlsirë pandispanjë ose kadaif të zhytur në sherbet, i cili ishte shumë i trashë dhe shumë i ëmbël për shijen evropiane."

Kur ata u kthyen tek hani i tyre, thashethemet kishin mbërritur para tyre. Hanxhiu u ngrit nga shiltja që ishte te porta e hanit, ku ai zakonisht kotej gjatë orëve të drekës, kur ishte vapë dhe i pyeti: "Është e vërtetë që ju paguat gjysmë napoloni për darkën mbrëmë? Tani, le të shohim, të bëjmë pak llogarinë, sa pjata hëngrët?" Ky ishte kulmi...

Vështirësia e parë gjatë vizitës në Shqipëri ishte gjuha, jo aq vetë gjuha shqipe në vetvete, sesa magnituda e gjerë e ndikimit të gjuhëve të ndryshme, të cilat ishin pasojë e `valëve të ndryshme të luftërave evropiane` dhe gjurmët që kishin lënë ato në gjuhën shqipe. Zakonisht të huajt që vinin në Shqipëri, nuk kuptonin asnjë fjalë në shqip dhe kjo ishte një vërejtje e hershme e vendasve. Por dy miqtë anglezë kishin ardhur disi të përgatitur. Në fakt 


\section{Albanon}

ata kishin mësuar dialektin toskë që përdorej në jug të vendit. Ata ishin të ndërgjegjshëm se do të kishin vështirësi në këtë drejtim. Elbasani ndodhej mbi lumin Shkumbin, i cili ishte kufiri që ndante toskërishten nga gegërishtja dhe Elbasani vetë anonte më shumë nga varianti i gegërishtes, që ishte dialekt karakteristik për veriun e Shqipërisë.

Megjithatë, me pak dëshirë të mirë, elbasanasit jo vetëm që mundoheshin t'i kuptonin mërmëritjet e tyre të mundimshme, por edhe i ndihmonin ata duke ia lehtësuar komunikimin. Autori shpesh përdor përemrin e vetës së parë shumës 'ne', duke nënkuptuar veten dhe të shoqen, edhe pse ishte e shoqja që bënte gjithë 'punën e mundimshme të komunikimit. Ajo kishte hartuar një fjalor të vogël, ku kishte shënuar gjithë shprehjet e domosdoshme të komunikimit të përditshëm. Ishte ajo që punonte me ngulm për të përvetësuar sa më mirë njëmbëdhjetë variantet e foljeve të rregullta, ndryshimet dhe format e pafund të foljeve të parregullta dhe akoma më shumë pjesët e tjera të parregullta të gramatikës së gjuhës shqipe.

Një vështirësi tjetër që ndeshën gjatë vizitës në Shqipëri dy udhëtarët anglezë ishte monedha. Shqipëria, në atë kohë, kishte për bazë floririn. Kjo mund të duket e habitshme, por ishte e vërtetë. Monedha standarde ishte 'napolon floriri me vlerën e 20 frangave të ditëve të para të Luftës së Parë Botërore. Elbasani ishte një koleksion i vërtetë monedhash. Autori kujton disi me humor: "Ishte diçka dëshpëruese që kuleta vazhdimisht të zbrazej, dhe të lehtësohej nga monedhat angleze apo frangat, dhe të rëndohej me një grusht monedhash argjendi, saqë edhe xhepat nuk $i$ mbanin dot". Konfuzioni i monedhave i solli në mendje autorit shumë histori të vjetra dhe kujtime shumë të gjalla. Ai filloi të kujtojë episod pas episodi dhe t’i krahasojë ato me zakonet shqiptare.

Udhëtari, që vjen nga Tirana në Elbasan nga Qafa e Kërrabës me çfarëdo mjeti dhe që do t’i duhet të kalojë një natë në hotelin Adriatik, nuk arrin t`i kuptojë cilësitë dhe vlerat e Elbasanit dhe aq më shumë t’ i shijojë ato. Elbasani nuk është një qytet ku ti mund të sorollatesh kot e të ndalosh vend e pa vend, aq më shumë nuk ia vlen ta kalosh kohën nëpër kafenetë e tij. Ato janë vende jo të këndshme, të zymta, të zbukuruara me figura oleografike femrash me gjoks të madh, me bel të hollë, 'meskëputur', të këndshme e të ëmbla. Këto piktura ishin bërë 40 vjet më parë. Kafenetë ishin vazhdimisht të zëna nga grupe të rastësishme, që ndryshonin herë pas here, grupe shqiptarësh të qethur me kujdes, që luanin me letra, domino ose ndonjë lojë tjetër, me një pasion të çuditshëm e nerva të tendosura. Pra, autori nuk i këshillonte këto vende nëse dikush donte vërtet të njihte Elbasanin. Ai thoshte se vendi më i 
mirë ku mund të pije kafe shumë të mirë turke dhe cigare, apo të hidhje një vështrim të përgjithshëm për Elbasanin, ishte floktorja. Autori nuk ishte i dhënë pas duhanit, madje nuk e pinte fare, por e përmendte atë se ashtu i kishin thënë, për forcë zakoni, duke përmendur edhe një thënie që përdorej shpesh në Elbasan: "Kafja pa duhan, si turku pa iman".

Në librin e tij ai përmend me radhë vende ku mblidheshin njerëzit për muhabet apo për të marrë vesh lajmet e ditës.

Një vend tjetër po kaq i këndshëm ishte edhe dyqani i argjendarit, ku me lehtësi mund të filloje të bëje pazar për një kohë të gjatë, edhe për një palë pineska apo kapse të vjetra argjendi, me figurën e Krishtit të gdhendur në to. Atje gjithashtu mund të gjeje varëse për 'nazar' apo 'nuska' të vjetra argjendi. Edhe në këtë vend mund të pije gjithashtu kafe shumë të mirë.

Gjithashtu kush dëshironte mund të shkonte te lëkurëpunuesi, të cilin mund ta gjeje gjithmonë duke punuar, ose duke bërë ndonjë samar gomari, ose ndonjë çantë shpine, ose duke bërë frerë dhe sipas zakonit edhe ky do të të qeraste me kafe.

Një vend tjetër, po aq i frekuentuar ishte edhe rrobaqepësi. Njerëzit që vinin aty, dëgjonin me vëmendje policin që lexonte gazetën me zë të lartë. Ose mund të shkoje e të rrije shumë rehat te duhanxhiu e të bisedoje gjatë me të. Gjatë bisedës ai vazhdonte të punonte, duke zgjedhur me kujdes gjethet e duhanit të mrekullueshëm që rritej në Elbasan. Ai i priste ato me një saktësi të hatashme, duke përdorur një aparat shumë primitiv. Po aty mund të shihje edhe vajzën e vogël të duhanxhiut, që spërkaste me ujë duhanin e sapogrirë, me qëllim që të mbante lagështirën dhe butësinë e duhur.

Po të dëshiroje mund të shkoje te dyqani i çajit, ku mund të pije çaj mali me aromë të mrekullueshme, disi të panjohur për shijen e të huajve. Ky dyqan ishte pronë e një hoxhe.

Në të gjitha këto vende që përmend autori, kushdo mund të ndiente ngrohtësinë elbasanase, mund ta prekte atë me duart e veta. Këto vende do t’ $\mathrm{i}$ jepnin mundësi ‘aromës së mrekullueshme të Elbasanit të hynte në gjithë organet e frymëmarrjes së çdo vizitori. Dhe pasi ta prekte vetë Elbasanin, atij do t $\mathrm{i}$ jepej mundësia të bisedonte rreth tij, ta eksploronte atë. "I gjithë Elbasani është një dyqan paksa i ekzagjeruar, nëse mund të shprehem kështu - shkruan autori. - Me 10.000 banorë Elbasani kishte pothuajse 1000 dyqane, pa numëruar këtu nëpunësit zyrtarë, gratë dhe fëmijët. Dukej sikur çdo familje në Elbasan kishte dyqanin e vet, natyrisht sipas llojit të familjes." 


\section{Albanon}

“ - Është e vërtetë se si rregull ishte diçka domosdoshmërisht e nevojshme, por edhe herë-herë barrë t’i mbaje këto dyqane. Mesatarja e përgjithshme e sipërfaqes së çdo dyqani ishte rreth 'dhjetë këmbë katrore', që me sistemin metrik është afërsisht $1.2 \mathrm{~m}$ me $2 \mathrm{~m}$ dhe me një qera rreth 6 paunde dhe 10 shilinga në vit. Konkurrenca mes tyre ishte shumë e madhe. Problemi i përhershëm ishte që dyqani të mbante të pandryshueshëm pronarin e vet. Miqtë e autorit, që ishin nga Amerika, kishin një dyqan shumë më të madh se ato të zakonshmit. Edhe pozicioni i dyqanit të tyre ishte në pozicion më të mirë sesa ai i dyqaneve të tjera. Qeranë ata e kishin 16 paunde në vit, megjithëse autori mendonte se asnjëherë gjatë sorollatjeve të tij dhe të së shoqes nuk i kishin parë ata të shisnin gjëra me vlerë që të përligjnin qeranë e madhe.

Gjithashtu, mund të thuhet se 'shpirti modern' i mbajtjes gjallë të këtyre dyqaneve po zhvillohej, sado që konkurrenca ishte shumë e madhe dhe mbijetesa e tyre ishte shumë e vështirë. Bëhej pazar për ulje çmimesh mes dyqanxhinjve dhe klientëve, por jo ndonjë pazar kushedi çfarë; dukeshin aty-këtu elementë të një shpirti tregtar, që mendjes së një tregtari modern do t`i dukeshin qesharake, zbavitëse, dhe pse jo, edhe absurde.

Një pasdite autori doli të blinte qershi. Ishte ditë feste dhe shitësit e zakonshëm të qershive ishin zhdukur nga qoshja e pazarit. Ai mezi gjeti një shitës ambulant që po shiste qershi. E pyeti për çmimin. Qershitë nuk ishin aq të shtrenjta, por edhe pamja e tyre nuk ia vlente. Autori po ngurronte, nuk dinte sa të blinte. Papritmas dëgjoi shitësin që i tha: "Mos i bli këto qershi. Nuk janë të mira. Mund të gjesh qershi më të mira te qoshja në të djathtë.”. Autori u çudit nga këto fjalë që i tha shitësi i qershive, tundi kokën dhe $\mathrm{u}$ largua.

Një mbrëmje tjetër, shumë vonë, kur qëndrimit të tyre po i vinte fundi, kur ata sapo kishin ngrënë darkë dhe po hynin te porta e hotelit, një njeri i panjohur iu afrua atyre në errësirë dhe i la në dorë autorit një shumë të vogël koronash argjendi.

“- Ç’janë këto? - e pyeti autori.

“- Janë baraz me një napolon, kusuri i darkës së asaj nate - tha dhe u largua në errësirë. Me sa dukej ai ishte shtrënguar të kthente kusurin.

Kohë më vonë, miqtë anglezë ia treguan këtë histori një shqiptari të shëtitur, që kishte udhëtuar shumë. Ai e dëgjoi me vëmendje historinë dhe tha: 
“- Ç”ka këtu për t’u treguar? Edhe mua më kanë mashtruar, më kanë marrë më shumë para se çduhej, madje edhe në vendet më të qytetëruara, por ama nuk më është kthyer kusuri.

“- Tamam - u përgjigjën ata, - ti ke të drejtë. Çështja është se Shqipëria ende nuk i gëzon disa nga përparësitë e të qenurit plotësisht e qytetëruar.”

(vijon në numrin e ardhshëm) 